\title{
Beta and gamma dose rate attenuation in rocks and sediment
}

\author{
Riedesel, Svenja; Autzen, Martin
}

Published in:

Radiation Measurements

Link to article, DOI:

10.1016/j.radmeas.2020.106295

Publication date:

2020

Document Version

Peer reviewed version

Link back to DTU Orbit

Citation (APA):

Riedesel, S., \& Autzen, M. (2020). Beta and gamma dose rate attenuation in rocks and sediment. Radiation Measurements, 133, [106295]. https://doi.org/10.1016/j.radmeas.2020.106295

\section{General rights}

Copyright and moral rights for the publications made accessible in the public portal are retained by the authors and/or other copyright owners and it is a condition of accessing publications that users recognise and abide by the legal requirements associated with these rights.

- Users may download and print one copy of any publication from the public portal for the purpose of private study or research.

- You may not further distribute the material or use it for any profit-making activity or commercial gain

- You may freely distribute the URL identifying the publication in the public portal

If you believe that this document breaches copyright please contact us providing details, and we will remove access to the work immediately and investigate your claim. 
3 Svenja Riedese ${ }^{1}$ and Martin Autzen ${ }^{2}$

${ }^{1}$ Department of Geography and Earth Sciences, Aberystwyth University, United Kingdom

${ }^{2}$ Center for Nuclear Technologies, Technical University of Denmark, DTU Ris $\varnothing$ Campus, Denmark

6

7

\section{Abstract}

8

This paper explores the attenuation of beta and gamma dose rate in a radioactive and in an adjacent inert layer for $\mathrm{K}$, Th and $\mathrm{U}$, individually using Geant4 simulations. The simulated beta dose rate attenuation cannot perfectly be described by a single exponential function, thus the updated attenuation coefficients were obtained using two exponential functions with intercepts related to the different slopes. Attenuation coefficients and intercepts are provided in the manuscript. The newly obtained beta dose rate attenuation coefficients differ from the previously published values by a factor of 2 , which results in a larger attenuation of the beta dose rate, so that the infinite matrix dose rate is reached at $\sim 2 \mathrm{~mm}$ into the sediment and at $\sim 1.5 \mathrm{~mm}$ into a rock. The new gamma dose rate attenuation coefficients are in good agreement with previously published literature and it is shown that the infinite gamma dose rate is reached at $300 \mathrm{~mm}$ in wet sediment with a density of $2 \mathrm{~g}$ $\mathrm{cm}^{-3}$.

Dose rate attenuation; beta dose rate; gamma dose rate; rock surface dating; luminescence dating

\section{Introduction}



sediment or rock material to light (Huntley et al., 1985). During the subsequent burial, the mineral grains in the sediment or rock absorb energy, delivered by natural radiation. The absorbed energy per unit mass within the crystal is termed dose (measured in Gy) and the rate at which this dose is delivered is termed dose rate (Gy/ka). The dose rate calculation for a sediment sample taken for luminescence dating within a homogenous sediment matrix is straightforward (e.g. Durcan et al., 2015). Here the total dose rate to the sample is calculated by adding the internal alpha and beta dose rate of the grains, the effective external alpha, beta and gamma dose rate and the cosmic dose rate (all in Gy/ka). The simplicity of this calculation is due to the infinite matrix assumption (Aitken, 1985; Guérin et al., 2012) for the external dose rate for a luminescence sample taken from a homogenous sediment matrix. Based on the infinite matrix assumption, the rate of energy absorption within a volume greater than the range of the radiation is equal to the rate of energy emission (Aitken, 1985). The size of the volume in which this assumption holds true, is thus dependent on the range of the radiation. The range of the radiation depends on the type of particle, its energy, as well as, the material it moves through, i.e. grain size, density, water content, composition etc. Whereas alpha particles only have a range of a few $\mu \mathrm{m}$ in sediment, electrons generally have a range of a few millimetres in sediment (maximum ranges: $\sim 3.6 \mathrm{~mm}$ for $\mathrm{K}$ and $\sim 1 \mathrm{~cm}$ for U/Th-series, Continuous Slowing Down Approximation and ranges from the National Institute of Standards and Technology, NIST, database). Photons will be able to travel much further and usually influence sediment within $\sim 30 \mathrm{~cm}$ (Aitken, 1985, 1998). The dose rate depends on the radionuclide concentrations in the sediment and rock, typically $\mathrm{U}, \mathrm{Th}, \mathrm{K}$ and to a small extent $\mathrm{Rb}$. These radionuclide concentrations are considered to be homogenously distributed within the matrix.

Whilst the use of the infinite matrix assumption can be a valid approximation for luminescence dating of infinitely thick homogenous sediment sequences, the dose rate calculations in environments that are characterised by the deposition of different sediments, resulting in multilayer sequences, are more complex. Examples for such multi-layer sediment sequences can for 
example be found in coastal environments, which record multiple storm surges or tsunami deposits (e.g. Madsen et al., 2009; Riedesel et al., 2018) or in an archaeological context (e.g. Mercier et al., 2007; Schaarschmidt et al., 2019). In such settings, more than one of these sediment layers can influence the dose rate absorbed by the luminescence sample. Here, mostly variations in the gamma dose rate of the different sediment layers have to be taken into account. If in situ gamma dose rate measurements are not possible, contributions of different influencing layers have to be calculated manually (Guibert et al., 1998) or by using radiation simulation tools (e.g. Grine et al., 2007; Nathan, 2010; Guérin and Mercier, 2011 and 2012; Martin et al., 2015).

Another case, where the calculation of the dose rate requires more attention, is in luminescence dating of cobbles and buried rock surfaces (e.g. Chapot et al., 2012; Sohbati et al., 2012; Jenkins et al., 2018). The total dose rate to be determined for cobble or rock burial dating, depends on the dose rate delivered by the rock itself, the surrounding matrix, and the contribution of the cosmic dose rate. Although the main contribution of the dose rate is expected to be delivered by the rock itself, beta and gamma radiation emitted from the surrounding matrix will still influence the dose rate of the outer part of the rock or cobble. Thus, when taking samples for equivalent dose determination by drilling from the surface into the rock and slicing the core into thin discs, the dose rate delivered to each individual slice will depend on the depth at which it was taken from the rock (Sohbati et al., 2012). Due to the range of beta and gamma radiation, a correct estimate for the attenuation of beta and gamma dose rate from the sediment into the rock and within the rock is thus crucial for the correct calculation of a burial age of the cobble or the rock surface.

So far, in luminescence dating studies of multi-layer sediment sequences and in absence of in situ dosimetry measurements, the approach of superposition (Aitken, 1985) has been used to calculate the gamma dose rate delivered to a sample, by the influencing sediment layers.

To our knowledge, Bailiff and Aitken (1980) calculated the first linear attenuation coefficients 
attenuation coefficients for Th and $U$ beta dose rates. For gamma dose rate linear attenuation coefficients for $U$ were determined experimentally and by simulations (Aitken et al., 1985). The authors state that linear attenuation coefficients for gamma dose rates derived by $\mathrm{K}$ and Th are unlikely to differ significantly from those obtained for U. Sohbati et al. (2012) adjusted the attenuation coefficients for Th and $U$ of Aitken et al. (1985) for rock dating, so that it accounts for the differences in density between a sediment and a rock matrix, and assumed a linear attenuation coefficient for $\mathrm{K}$ beta dose rates. However, the applicability of the experimental setup used by Aitken et al. (1985) to a natural sediment sequence has not been tested yet. Additionally, a linear attenuation coefficient for beta dose rate by K has only been calculated (Bailiff and Aitken, 1980), but has never been verified by simulations or experiments.

This paper aims to fill these gaps in knowledge, by using the radiation transport code Geant4 (Agostinelli et al., 2003) running on a virtual machine (Incerti et al., 2010). The Geant4 toolkit has previously been applied in studying the beta and gamma dose rates in luminescence and EPR dating (e.g Guérin and Mercier, 2011; Martin et al. 2014, 2015). Guérin and Mercier (2011) modelled the gamma dose rate in infinitely thick sediments spheres for in situ gamma spectrometry. Martin et al. (2015) showed a comparison of the beta and gamma dose rate in silica from their DosiVox software and other published values and found good agreement. Some of the simulations presented in the present study have been carried out by Martin et al. (2015). However, linear attenuation coefficients were not presented or discussed by Martin et al. (2015). Using simulations, we explore differences in beta and gamma dose rate attenuation of $\mathrm{K}$, Th and $\mathrm{U}$ in different substrates. Therefore, we use different combinations of active and inactive sediment and granite matrixes, to be able to provide the user with dose rate attenuation coefficients, which are specific for the decay chain, the substrate and the size of the matrix. Additionally, we explore the effect of different rock sizes on the fraction of infinite dose rate (measured at the centre of the rock and at the interface between the rock and the adjacent sediment) and on the attenuation coefficients. 
Aitken et al. (1985) used an experimental laboratory setup (modified from Bailiff and Aitken, 1980; see Fig. 1) to measure the attenuation of the beta dose arising from the U- and Th-decay series. The beta dose given to a $\mathrm{CaF}_{2}$ sample in a copper tray by a pitchblende source (for $\mathrm{U}$ ) and a monazite source (for Th) was measured by inserting aluminium absorbers of different thicknesses between the source and the sample to attenuate the dose rate. The measured attenuation coefficients using the aluminium absorbers were $1.54 \mathrm{~mm}^{-1}$, and by $1.78 \mathrm{~mm}^{-1}$ for the U-series and Th-series, respectively. Based on these results, Aitken et al. (1985) calculated the attenuation for absorption in wet sediment by scaling for the differences in density between wet sediment $(2.0 \mathrm{~g}$ $\left.\mathrm{cm}^{-3}\right)$ and aluminium $\left(2.7 \mathrm{~g} \mathrm{~cm}^{-3}\right)$, which yielded beta attenuation factors of 1.14 and $1.32 \mathrm{~mm}^{-1}$ for $U$ and Th, respectively.

For gamma dose rate attenuation, Aitken et al. (1985) used a combination of experimental measurements and simulations. By using the experimental setup of a $\mathrm{CaF}_{2}$ dosimeter placed on top of glass attenuators, which separated the sample from a concrete block doped with $U$, Aitken et al. (1985) obtained a linear attenuation factor of $0.02 \mathrm{~mm}^{-1}$. For larger distances, Aitken et al. (1985) used the radiation transport code by Kirkegaard and Løvborg (1980), which resulted in an attenuation of $0.011 \mathrm{~mm}^{-1}$. In Aitken (1985), a linear gamma dose rate attenuation factor of 0.015 $\mathrm{mm}^{-1}$ is given for $\mathrm{U}$, which is based on the two results, obtained by the previously described combination of experiments and simulations. Aitken (1985) then assumes the same attenuation for Th. 

attenuation in different substrates, we first simulated the original experiment, which measured beta dose rate attenuation for Th and U, by Aitken et al. (1985). The beta spectra used are from Guérin et al. (2012). We recreated the geometry of Aitken et al. (1985, Fig. 1) using the radiation transport code Geant4. To optimise the simulations, we excluded the plastic foil and the Perspex holder from our simulations. The Perspex holder does not contribute to the dose deposited in the $\mathrm{CaF}_{2}$ sample, but excluding it decreases the simulation time. The Melinex film (plastic foil), used in the original experimental setup, removes any alpha particles emitted from either of the two sources used by Aitken et al. (1985) but does not influence the beta dose rate. By using simulations we can emit pure beta spectra from the simulated sources, and thus do not need to account for any emitted alpha particles. The emission of a pure beta spectrum in the simulations also makes the subtraction of any gamma dose emitted by the pitchblende or monazite source, as done by Aitken et al. (1985), unnecessary.

In the Geant4 simulations we used a $5 \mathrm{~mm}$ thick monazite and a $5 \mathrm{~mm}$ thick pitchblende source for the Th- and U-series, respectively (A.S. Murray, private communication). For both, we tested attenuation through $\mathrm{Al}$ absorbers as well as through sediment absorbers (wet density of $2.0 \mathrm{~g}$ The results of the simulations are shown in figures $2 A-D$. Using aluminium absorbers (circles) we are able to reproduce the experimental data of Aitken et al. (1985, dashed line) for both, Th and U. However, we observe a slight deviation from a single exponential in case of Th, when the absorber thickness exceeds $2 \mathrm{~mm}$ (Fig. 2B). We also tested the density correction performed by Aitken et al. (1985) in order to convert the attenuation factor obtained for aluminium absorbers in 
figures $2 A-D$ as squares and the corresponding fit from Aitken et al. (1985, dashed line) shows good agreement with the simulation results. Above a sediment attenuator thickness of $1.5 \mathrm{~mm}$, the attenuation of the beta dose rate delivered by Th no longer follows a single exponential (Fig. 2B, squares) and this deviation is even more pronounced than for aluminium absorbers (Fig. 2B, circles). By fitting the simulated data with an exponential function (linear regression on a natural logarithm scale), we obtain linear attenuation coefficients in good agreement with the results of the original experiments, using Al absorbers, and the calculations for sediment absorber by Aitken et al. (1985 and Table 1). As a final test, we also used $1 \mathrm{~cm}$ thick sediment sources instead of the monazite and pitchblende sources. In each simulation the dose is recorded in a $1 \mathrm{~mm}$ thick $\mathrm{CaF}_{2}$ resin mixture. Using sediment sources instead of monazite and pitchblende does not change the linear attenuation factors.

Despite good reproducibility, the experimental setup used by Aitken et al. (1985) and in our simulations, differs significantly from a natural sediment sequence sampled for luminescence dating, but we can use Geant4 to replicate natural irradiations and compare the attenuation coefficients from these with those of the experimental setup described by Aitken et al. (1985).

\subsection{Simulation of beta dose rate attenuation in a sediment matrix}

To investigate the attenuation of $\mathrm{K}, \mathrm{Th}$, and $\mathrm{U}$ beta dose rates in a more natural setup, we constructed a geometry consisting of a cylindrical wet sediment matrix with an active and an inactive distance. In order to test the validity of the geometry as an infinite matrix, we calculated the fraction of infinite matrix dose rate at the interface between the active and inactive layers and obtained a 
value of $50 \%$ (see Fig. 4). This is in agreement with the symmetry argument (Aitken, 1985, appendix H). Although the fractional dose rate at the interface is $50 \%$, the subsequent attenuation differs in the active and the inactive layer.

Figure 4 shows the simulated data of the attenuation of the beta dose rate delivered by $\mathrm{K}$, Th and $U$ on a linear and on a natural logarithmic scale. Independent of the decay chain, infinite beta dose rate is reached at $\sim 2.0 \mathrm{~mm}$ into the active layer. To obtain linear attenuation coefficients, the

and equation 2 on the inactive side

$$
\frac{\dot{D}(x)}{\dot{D}_{\text {inf }}}=0.5 e^{-\mu \cdot x}
$$

Here $\mu$ is the linear attenuation coefficient and $\mathrm{x}$ is the distance into the layer.

To show the deviation of the fit to the simulated data, residuals were calculated by subtracting the fitted data from the simulated data. The attenuation of the beta dose rate in the active and inactive layer, delivered by $\mathrm{K}$, is well described by equations 1 and 2 , respectively. However, the attenuation of beta radiation of Th and $\mathrm{U}$, in active and inactive sediments, does not follow equations 1 and 2 perfectly (Figs. 4C-F). The largest difference between the simulated and the fitted data, for $U$ and Th, respectively, is found in the first $200 \mu \mathrm{m}$ of either layer. Calculating the natural logarithm of the simulated data reveals a difference in attenuation in the beta dose rate, when comparing the attenuation of the first $200 \mu \mathrm{m}$ and the rest of the layer. To explore the differences and to be able to provide attenuation coefficients, which describe the simulated data better, we used equations 3 and 4 for fitting the active and inactive side, respectively. 


$$
\dot{D}(x)=\left\{\begin{array}{c}
1-0.5 e^{-\mu_{1} \cdot x}, \quad x<z \\
1-f * e^{-\mu_{2} \cdot x}, \quad x>z
\end{array}\right.
$$

and the inactive side by using

$$
\dot{D}(x)=\left\{\begin{array}{cc}
0.5 e^{-\mu_{1} \cdot x}, & x<z \\
f * e^{-\mu_{2} \cdot x}, & x>z
\end{array}\right.
$$

where $\mu_{\mathrm{i}}$ is the linear attenuation coefficient corresponding to slope $i$ and $f$ is the intercept of that slope. Since the dose rate attenuation on the active and inactive side in sediment is symmetrical (Fig. S1), the same attenuation coefficients can be used for both sides (Table 2).

Fitting two linear regression curves to the data on a natural logarithmic scale reveals an initial attenuation $2.4 \pm 0.04$ times larger than after $200 \mu \mathrm{m}$ (Table 2). This implies that the attenuation of the beta dose rate delivered by Th and $U$ is more complex than can be described by a single saturating exponential function.

After $200 \mu \mathrm{m}$ on the active side, the impact of the deviation of our simulated data from a single exponential function is at most $5.5 \%$ ( $U$ beta) in the case of $U$ beta (see residuals in Fig. 4E). At this depth into the active layer, the fraction of infinite beta dose rate is $75 \%$. A deviation of $5.5 \%$ of the fitted data to the simulated data would thus result in a $5.5 \%$ underestimation of the dose rate at this point, since the fit underestimates the simulation results in this case. The deviation of the fitted data to the simulated data, after $200 \mu \mathrm{m}$, is less pronounced for $\mathrm{K}$ and Th. Within the first $200 \mu \mathrm{m}$, the single exponential fit deviates up to $11 \%$ (Th beta) from the simulated data in the case of Th beta (see residuals in Fig. 4C).

Whilst the impact of the deviation on the dose rate is within reason for the active side, there are large relative deviations on the inactive side, before and after $200 \mu \mathrm{m}$. This is due to the fraction of the infinite dose rate being much smaller on the inactive side. Thus the same absolute deviations as on the active side will result in larger relative deviations on the inactive side. In the case of the inactive side, the fit overestimates the dose rate up to $0.5 \mathrm{~mm}$ to a maximum of $22 \%$ (Th beta). After $0.5 \mathrm{~mm}$ the fraction of infinite beta dose rate is only $13 \%$. Subsequently a small deviation will 
result in large relative residuals between the simulated and the fitted data. However, these deviations will only have an impact on the final age, when the luminescence sample has been taken from a weak radioactive sediment layer, close to the boundary to a highly radioactive sediment layer.

The obtained attenuation coefficients for $U$ and Th are twice as large as those presented by Aitken et al. (1985) and those obtained by recreating the original experiments from Aitken et al. (1985, see section 2 of the present study). We investigated the difference between the attenuation factors for Th and $U$, by varying the simulation setup. We found that the attenuation factors are dependent on the thickness of absorbers used, with an observed decrease in attenuation with increasing absorber thickness, when investigating the absorption through the attenuators. Thus, by changing the thickness of the absorber, it is possible that Aitken et al. (1985) influenced the dose rate attenuation factors calculated later. Additionally, our model predictions are supported by Brennan et al. (1997) who observed differences in beta dose attenuation in enamel when comparing the data of Aitken et al. (1985), Cross et al. (1992), and Grün (1986). They found that both Aitken et al. (1985) and Grün (1986) predicted higher doses at depth, thus smaller attenuation, than Cross et al. (1992) and their own simulations, both of which are supported by experimental observations. Martin et al. (2015) reproduced the data of Brennan et al. (1997) using their DosiVox software. Thus, we are confident that the newly simulated beta dose rate attenuation coefficients, presented in this paper, for $\mathrm{K}$, Th and $\mathrm{U}$ in sediment can be used as a good approximation for beta dose rate attenuation in nature.

\subsection{Gamma dose rate attenuation in sediment}

For OSL dating of sediment, variations in the gamma dose rate can have a large influence on the final age. Correctly defining the attenuation of gammas in sediment is thus crucial. We used the geometry shown in figure 3 , modified for gamma emission, to model the attenuation of the gamma 
dose rate in sediment and followed the same setup as for beta emissions, outlined in Section 3.1

(Fig. 3). Since gammas have longer ranges than electrons emitted during beta radiation, the detectors were changed to a thickness of $5 \mathrm{~mm}$ and radii of 86,125 and $115 \mathrm{~cm}$ for $\mathrm{K}$, Th, and $\mathrm{U}$, respectively. The sediment matrix was changed to radii of 258,375 and $345 \mathrm{~cm}$ for $\mathrm{K}$, Th and $\mathrm{U}$, respectively, and a length of $70 \mathrm{~cm}$ for the active and inactive layers each to account for the longer range of gammas. A test run was made with a length of $200 \mathrm{~cm}$ but we observed no difference in the location or value of the plateau, thus we chose the smaller volume to decrease simulation time. All gamma spectra were taken from Guérin and Mercier (2011). gammas, infinite gamma dose rate is only reached after $\sim 300 \mathrm{~mm}$ into the active sediment for $\mathrm{K}$, Th and $\mathrm{U}$. We fitted the simulated data with equations 1 and 2 for the active and inactive side of the sediment matrix, respectively. We observe a small deviation from a single exponential on the active and inactive side for all three decays, although it is less pronounced for $\mathrm{K}$ than for Th and $\mathrm{U}$ and the residuals are very small $(<1 \%)$, leading to the conclusion to use a single exponential to fit the recorded data points to obtain attenuation factors for sediment. A change in slope for the attenuation of gamma radiation delivered by $U$ has already been observed by Aitken et al. (1985). Experimental evidence suggested an attenuation of $0.02 \mathrm{~mm}^{-1}$ in the first $20 \mathrm{~mm}$, whilst simulations resulted in an attenuation of $0.011 \mathrm{~mm}^{-1}$ for distances $>20 \mathrm{~mm}$. Aitken (1985, p. 293-294) subsequently suggests to use a linear attenuation factor of $0.015 \mathrm{~mm}^{-1}$. The linear attenuation coefficients obtained in the present study (Table 2) are not only in good agreement with the results of Aitken et al. (1985), but also with Monte Carlo simulations performed by Martin et al. (2015). We performed additional simulations, to explore physical reasons behind the change in slope of the active and inactive side for Th and $\mathrm{U}$ beta and gamma dose rate attenuation (see Fig. 4C-F). Initially we considered the change in slope could be due to the number of emitters in the $\mathrm{K}$ and Th or 
from $\mathrm{K}$, although this is a single line emission. Thus, the number of emitters in the spectrum cannot explain the change in slope. Additionally, we investigated the attenuation of primary and secondary electrons and bremsstrahlung of Th beta dose rates in a sediment matrix. We observe identical attenuation to those shown in Figure $4 C$ and $D$, with two slopes being present, for primary and secondary electrons. Bremsstrahlung shows lower attenuation, than primary and secondary electrons, however, also the attenuation of bremsstrahlung is characterised by two slopes. Thus we are not able to physically explain the occurrence of two slopes in the attenuation of dose rates from different decay chains for betas and gammas.

\section{Beta and gamma dose rate attenuation in granite and variations with rock size}

With the increasing use of cobbles and rocks in luminescence dating studies, accurate constrains of the beta and gamma dose rate attenuation in rock is important. Our simulations were performed in a granite matrix $(33 \% \mathrm{Si}, 7.6 \% \mathrm{Al}, 3.4 \% \mathrm{~K}, 2.7 \% \mathrm{Na}, 1.3 \% \mathrm{Ca}, 2.15 \% \mathrm{Fe}, 0.42 \% \mathrm{Mg}$, $0.018 \% \mathrm{Ti}, 0.05 \% \mathrm{P}, 0.03 \% \mathrm{Mn}$, and $49.1 \% \mathrm{O}$ ), with a density of $2.7 \mathrm{~g} \mathrm{~cm}^{-3}$. Since the cobble might be situated in an entire layer of rocks or as a single cobble in a sediment section, different substrates as surrounding matrix and their influence on the dose rate attenuation into the cobble were also explored. The following section presents simulation results of the attenuation of beta and gamma dose rates delivered by $\mathrm{K}, \mathrm{Th}$ and $\mathrm{U}$ in granite (active and inactive), in granite as an active matrix and an adjacent inactive sediment matrix and vice versa. Additionally, the influence of rock size on the fraction of the infinite matrix gamma dose rate at the interface and at the centre of the rock is investigated.

\subsection{Beta and gamma dose rate attenuation in granite}

A change in substrate, which goes along with a change in the density of this substrate, influences the attenuation of both, beta and gamma radiation, for the three decay chains 
investigated (namely $\mathrm{K}, \mathrm{Th}$ and $\mathrm{U}$ ). Table 3 presents the results of beta and gamma dose rate attenuation in granite for $\mathrm{K}, \mathrm{Th}$ and $\mathrm{U}$. The attenuation for both beta and gamma radiation is larger in granite than in sediments, reaching saturation at $\sim 1.5 \mathrm{~mm}$ and $170 \mathrm{~mm}$ into the rock, for beta and gamma dose rates, respectively. As already addressed for a wet sediment matrix, the only case, in which the dose rate attenuation follows a single exponential, is in the case of a beta dose rate delivered by $\mathrm{K}$. The same was observed for a granite matrix. For beta dose rates by Th and $\mathrm{U}$, and in all three cases for gamma dose rates, the attenuation cannot be explained perfectly by a single exponential function. In the case of beta dose rate attenuation the data was thus fitted using equation 3 and 4 for the active and inactive side, respectively. For gamma dose rate attenuation, small deviations $(<1 \%)$ of the simulated data from a single exponential fit, lead to the conclusion to use equations 1 and 2 for fitting the data.

As long as the inactive and active matrix substrates are identical, the symmetry argument holds true and the same attenuation coefficients can be used for the active and inactive side, respectively (Fig. S1). However, in those cases where the substrates of the two adjacent matrices differ, individual attenuation coefficients for granites and sediments are to be used when calculating dose rates for the active and inactive sides. The attenuation coefficients for granite are provided in table 3.

\subsection{Fraction of infinite matrix gamma dose rate depending on rock size}

So far, the principle of symmetry by Aitken (1985) has been used to determine the internal beta and gamma dose rate to different depths into a rock. This means that the dose rate at the interface between the cobble and the surrounding matrix has, in some cases, been assumed to be 50 $\%$ of the infinite dose rate of the cobble. Whilst this will be valid for betas due to their short range (see Fig. 4), for gammas the fraction of infinite matrix dose rate at the interface and at the centre of the cobble will depend on its size. The latter was investigated by placing $1 \mathrm{~mm}$ thick concentric shells 
of active granite in a $5 \mathrm{~m}$ diameter spherical inactive sediment matrix and by varying the absolute size of the spherical cobble (Fig. 6A). Figure 6B shows the fractional infinite matrix dose rate on the interface and at the centre of the spherical cobble as a function of the sphere's diameter. As the cobble becomes larger, getting accurate dose rates at the central volume requires very long simulation times. However, for cobbles of diameters of $2.5,5$, and $10 \mathrm{~cm}$ we obtained a ratio of 2 between the dose rate at the centre and the outermost volume. This ratio was then used to calculate the central dose rate for larger cobbles. The fractional infinite matrix dose rate follows

$$
\dot{D}_{\text {edge }}=0.5 \cdot\left(1-e^{-p \cdot x}\right),
$$

where $\dot{D}_{e d g e}$ is the fractional infinite cobble matrix dose rate at the interface of the rock and the surrounding sediment, $x$ is the diameter of the cobble and $p$ is the build-up. From fitting the simulated data with a single saturating exponential (Fig. 6B) we obtain a value of $p=0.039 \mathrm{~cm}^{-1}$ for dose rate at the edge and at the centre of the cobble. Up to a rock diameter of $10 \mathrm{~cm}$ the results of the simulations in figure 6B are in good agreement with data presented by Mejdahl (1983). Mejdahl (1983) used available Monte Carlo data by Brownell et al. (1968) and Ellett and Humes (1971) and corrects those for the density of sherd $\left(2.0 \mathrm{~g} \mathrm{~cm}^{-3}\right)$ and rock $\left(2.6 \mathrm{~g} \mathrm{~cm}^{-3}\right)$ to calculate the absorbed fraction of gamma dose rate in those substrates. Subsequently, Aitken (1985) highlights a relationship between the average gamma dose rate to a spherical cobble of density $2.6 \mathrm{~g} \mathrm{~cm}^{3}$ and its diameter d, based on the data by Mejdahl (1983) of 2.6d\% for diameters up to $9 \mathrm{~cm}$ (inset Fig. 6B).

As already mentioned in relationship to the original experiment conducted by Aitken et al. (1985), who constrained beta dose rate attenuation in a laboratory experiment, the attenuation coefficients change with the thickness of absorbers. We tested the influence of cobble size on the linear attenuation coefficients. Figure $6 \mathrm{C}$ shows how the linear attenuation coefficient varies with cobble diameter: the attenuation coefficient decreases with increasing cobble diameter until reaching the value found for the infinite matrix, see Table 3. Linear attenuation coefficients for a 
range of cobble diameters are given in Table S3. The equation used for fitting is also given in the supplementary material. surfaces Calculating accurate beta and gamma dose rates to sediments and cobbles is very important in luminescence dating in order to obtain correct ages. This requires knowledge of the attenuation of both beta and gamma dose rates, which have so far been calculated using the linear attenuation coefficients provided by Aitken et al. (1985) and Aitken (1985). Using Geant4 modelling, we were able to simulate a more natural setup and obtained linear attenuation coefficients for beta and gamma radiation of $K$, Th and $U$ in sediment and granite. We have compared these new linear attenuation coefficients to those presented by Aitken et al. (1985) and Aitken (1985) and found linear beta attenuation coefficients for sediments twice as large as those currently used for $\mathrm{K}$, Th and $\mathrm{U}$ in sediment and granite (Aitken et al., 1985; Aitken, 1985; Sohbati et al. 2012). Our results for the attenuation of gamma dose rates for Th and $U$ is in good agreement with findings by Aitken et al. (1985) and Aitken (1985).

\subsection{Impact of updated dose rate attenuation factors in the context of sediment dating}

In the case of luminescence dating of sediments, the updated beta dose rate attenuation coefficients will not significantly affect previously published results. Although the linear beta attenuation coefficients presented in this paper are twice as large as those presented by Aitken et al. (1985) and Aitken (1985), this will generally not have an impact on sediment dating, unless samples are taken in extreme close proximity (within $2 \mathrm{~mm}$ distance) to a boundary. This is due to infinite matrix beta dose rate being reached completely after $2 \mathrm{~mm}$ from the boundary in the case of all three decay chains investigated. 
In the case of gamma attenuation, the updated coefficients do not differ significantly from those presented by Aitken et al. (1985) and Aitken (1985). This is likely due to the fact that at distances above $20 \mathrm{~mm}$ the linear attenuation coefficients were simulated using Monte Carlo (using the code produced by Kirkegaard and Løvborg, 1980) and the cross-sections have not been updated significantly in the past 35 years. Our simulations support the change in slope already observed by Aitken et al. (1985) resulting in a deviation from a single exponential. The impact of this change in slope on the gamma dose rate delivered to the sample is relatively small.

\subsection{Impact of updated dose rate attenuation factors on cobble dose rates}

In cobble dating, due to high-resolution sampling close to boundaries between the rock and the adjacent sediment, this work will have a variable impact on the dose rate calculations, dependent on rock and sediment radioactivity and cobble size. The newly obtained linear attenuation coefficients will help to obtain more accurate luminescence ages.

Due to the higher attenuation of dose rates using the new attenuation coefficients presented here, the beta dose rate of the cobble itself will have an even larger influence on the total beta dose rate delivered to each individual rock slice. The largest differences on the active side between our newly obtained attenuation coefficients and those calculated by Sohbati et al. (2012) (based on Aitken, 1985, and Aitken et al., 1985) will be $15 \%$ at $300 \mu \mathrm{m}$ into the cobble, for Th and U. For K, the difference will be even larger ( $23 \%)$, when comparing the assumed attenuation coefficient of Sohbati et al. (2012) and the simulated value for $\mathrm{K}$ beta dose rate presented here. Thus, for $\mathrm{K}$ we now not only update the currently used attenuation coefficient, but also provide a value that has been obtained using simulations of dose rate attenuation in granite.

Due to the smaller fractional dose rate on the inactive side even small absolute deviations between the two sets of attenuation coefficients will results in large relative differences. For 
example, relative differences of the attenuation of the beta dose rate delivered by Th and $U$, respectively, from the adjacent sediment into the cobble are between 70 and $90 \%$ at $300 \mu \mathrm{m}$ into the cobble. For distances further into the cobble, the differences between our simulation dose rates and those obtained by using those by Sohbati et al. (2012) will be even larger, which can be explained by the sediment dose rate reaching a fractional dose rate $<1 \%$ at $1 \mathrm{~mm}$ into the cobble, when using our attenuation coefficients. Using those calculated by Sohbati et al. (2012) the fractional beta dose rate of the sediment at $1 \mathrm{~mm}$ is still $~ 8 \%$, resulting in a difference of $748 \%$ for Th as an example. Thus, the influence of the sediment dose rate to the total beta dose rate of the rock slices will be smaller, when using the new attenuation coefficients for beta dose rates. At this distance, the gamma dose rate should already dominate the contribution from Th in the sediment to the cobble.

It is important to note that the fractional dose rate at the interface of a cobble cannot be assumed to be $50 \%$ of the infinite matrix gamma dose rate of the cobble itself (Mejdahl, 1979; Aitken, 1985, p. 292). Assuming a fractional dose rate of $50 \%$ at the interface will result in in an overestimation of the dose rate at the interface of up to $48 \%$, depending on the size of the cobble. Overestimating the fractional dose rate at the interface will lead to an overall overestimate of the dose rate to a slice taken from the cobble as well. Additionally, the linear attenuation coefficient for gamma dose rates delivered by $\mathrm{K}$, Th and $\mathrm{U}$ have to be adapted depending on cobble size (Fig. 6C, Table S3), otherwise it will lead to overestimation of the gamma dose rate delivered by the cobble.

\section{Summary and conclusions}

This paper investigated the attenuation of beta and gamma dose rate delivered by the radioactive decay of $\mathrm{K}$, Th and $\mathrm{U}$ in active and inactive sediment and granite by using the radiation transport code Geant4 (Agostinelli et al., 2003). The simulated attenuation of beta dose rates into a sediment and a rock matrix can be described by a single exponential function in the case of $\mathrm{K}$, but for 
Th and $U$, a change in slope after $200 \mu \mathrm{m}$ leads to the use of fitting the simulated data using two exponential functions. In the case of gamma attenuation, two slopes were observed for all three decay chains, however the deviation of the simulated data from a single exponential function was less than $1 \%$, and thus a single exponential function was used to obtain linear attenuation coefficients.

According to the new results presented here, beta dose rate attenuation in sediment and rocks is twice as large as previously estimated (Aitken et al., 1985) and infinite matrix beta dose rate is reached after $\sim 2 \mathrm{~mm}$ into the sediment and after $\sim 1.5 \mathrm{~mm}$ into the rock. The new linear attenuation coefficients obtained for gamma dose rate attenuation in sediment, are in good agreement with published literature (Aitken et al., 1985 and Aitken, 1985), resulting in no significant changes to the coefficients to be used for attenuation into sediment. The gamma dose rate attenuation in granite is larger than in sediment, reaching infinite gamma dose rate at $\sim 170 \mathrm{~mm}$ into the granite matrix and at $300 \mathrm{~mm}$ into sediment. should be used when calculating dose rates for the active and inactive side. Another importance for burial dating of rock surface is that the fraction of the infinite gamma dose rate at the interface of the rock and the adjacent sediment depends on the size of the rock. Additionally, the rock size influences the gamma dose rate attenuation coefficients for the dose rate getting attenuated into the rock (both rock and sediment dose rates).

This paper not only updated linear attenuation coefficients for sediment and buried rock surface dating, but also highlighted the importance of the rock size on the gamma dose rate of the rock itself and will thus improve buried rock surface dating using luminescence. 

research. We would like to thank Prof G.A.T. Duller, Prof H.M. Roberts and Dr X. Ou (all Aberystwyth University) and Prof A.S. Murray (Aarhus University) for fruitful discussions, which helped to improve this research. We thank Prof I.K. Bailiff (Durham University) and Prof A.S. Murray (Aarhus University) who shared their knowledge on the original experimental setup presented in Aitken et al. (1985). We would like to thank two anonymous reviewers, whose comments helped to improve the manuscript.

\section{References}

Aitken, M.J., 1985. Thermoluminescence Dating. Academic Press, London, 184 p. Collaboration). 2003. Geant4 - a simulation toolkit. Nuclear Instruments and Methods in Physics Research Section A. 506(3), 250-303. internal beta dose-rate in archaeological dating. Nuclear Instruments and Methods 173, 423-429. tooth enamel by "one-group" theory and the Rosy ESR dating software. Radiation Measurements 27, 307-314. 

age of rock art my dating a rockfall event using sediment and rock-surface luminescence dating techniques. Quaternary Geochronology 13, 18-25. water. AECL Research report AECL-10521. charge dating. Quaternary Geochronology 28, 54-61.

Ellett, W.H., Humes, R.M., 1971. Absorbed fractions of small volumes containing photonemitting radioactivity. Journal of Nuclear Medicine, MIRD Supplement Number 5, 25-32. Physical Measurements Laboratory. https://physics.nist.gov/PhysRefData/Star/Text/method.html and Pike, A. W. G., 2007. Late Pleistocene human skull from Hofmeyr, South Africa, and modern human origins. Science 315(5809), 226-229.

Guérin G., Mercier N., 2011. Determining gamma dose rates by field gamma spectroscopy in sedimentary media: results of Monte Carlo simulations. Radiation Measurements 46: 190-195 potential of non-invasive measurements. Geochronometria 39: 40-47 matrix assumption and associated concepts: A critical review. Radiation Measurements 47, 778-785. 
Incerti, S., Baldacchino, G., Bernal, M., Capra, R., Champion, C., Fracis, Z. Guèye, P., Mantero, A.,

Mascialino, B., Moretto, P., Nieminen, P., Villagrasa, C., and Zacharatou, C., 2010. The Geant4-DNA tabulated data and standard calculations. Ancient TL 33, 1-9. 364. (Morocco): Chronology of the mousterian and aterian archaeological occupations and their implications for Quaternary geochronology based on luminescence (TL/OSL) age determinations. Quaternary Geochronology 2, 309-313. dating. DPhil Dissertation, Archaeology, University of Oxford (UK) 
505 Tamura, T., Burow, C., Cunningham, A., Seeliger, M., De Batist, M., Heyvaert, V.M.A., Fujiwara, O., 506 Brückner, H., the QuakeRecNankai Team, 2018. Single-grain luminescence chronology of historical 507 extreme-wave event deposits recorded in a coastal lowlands, Pacific coast of central Japan. 508 Quaternary Geochronology 45, 37-49. and IR-RF dating of archaeological deposits at Badahlin and Gu Myaung Caves - First luminescence ages for Myanmar. Quaternary Geochronology 49, 262-270. 2019. Optical bleaching front in bedrock revealed by spatially-resolved infrared photoluminescence. Scientific Reports 9(1), 2611 


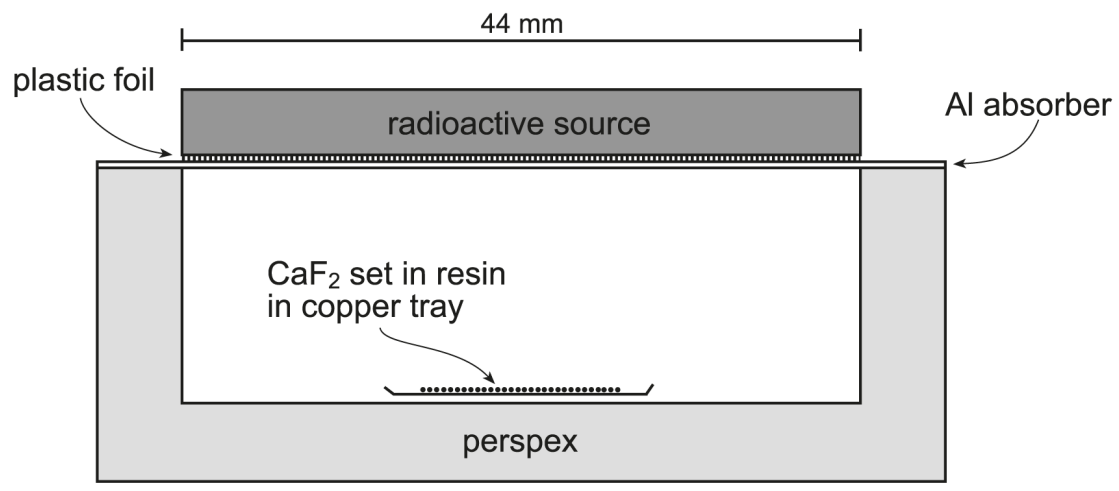

Fig. 1: Cross-section of the original experiment by Aitken et al. (1985), which was recreated

522 using the radiation transport code Geant4. The experimental setup was originally used in Bailiff and

523 Aitken (1980) and further details for our simulations were given by I. K. Bailiff (personal

524 communication). The plastic foil (Melinex film) was not included in the simulations. The radioactive

525 source is $5 \mathrm{~mm}$ thick for monazite and pitchblende.
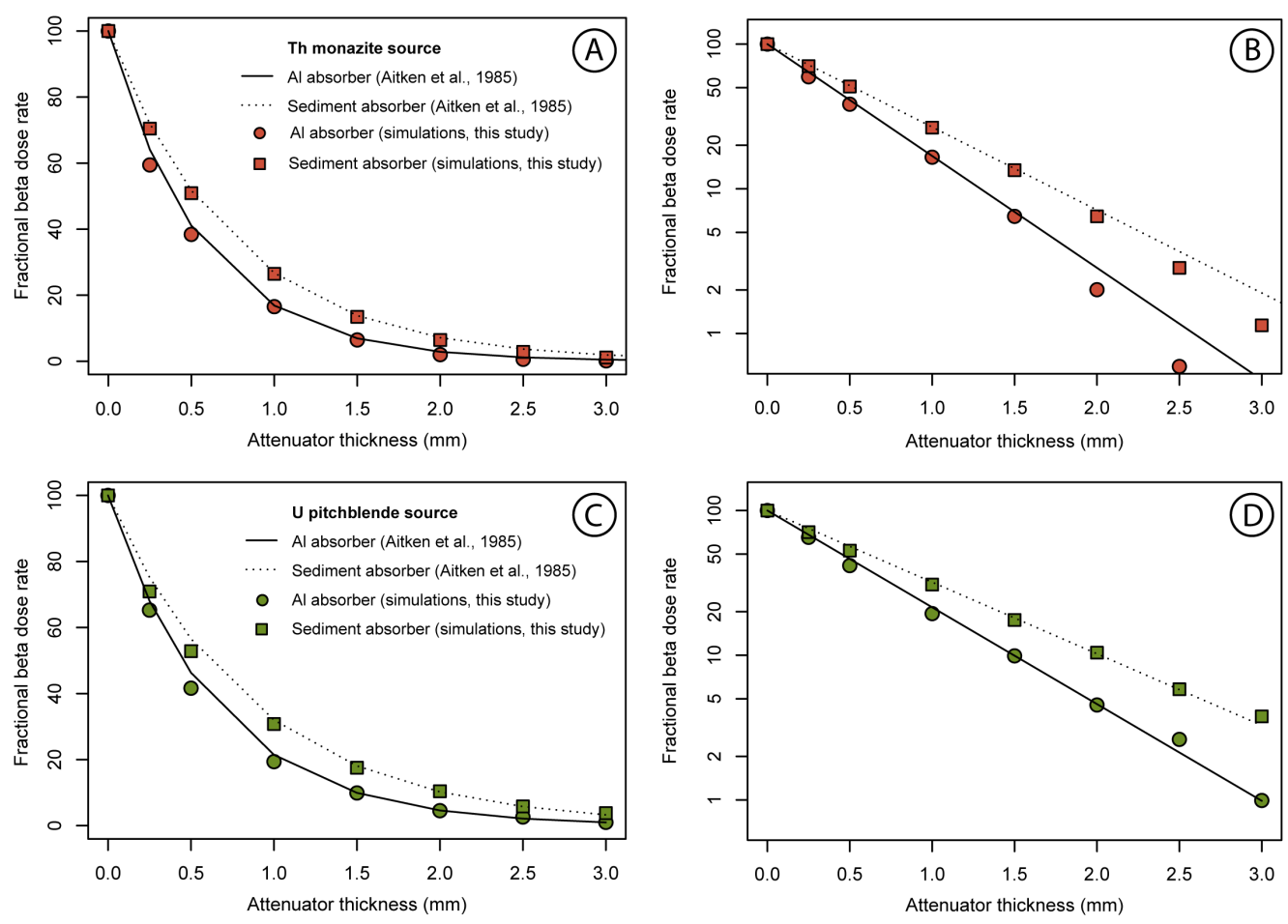

Fig. 2: Comparison of beta dose rate attenuation through aluminium and sediment absorbers as presented by Aitken et al. (1985) and by simulating the experimental setup for Al and sediment 

natural logarithmic scale.

532
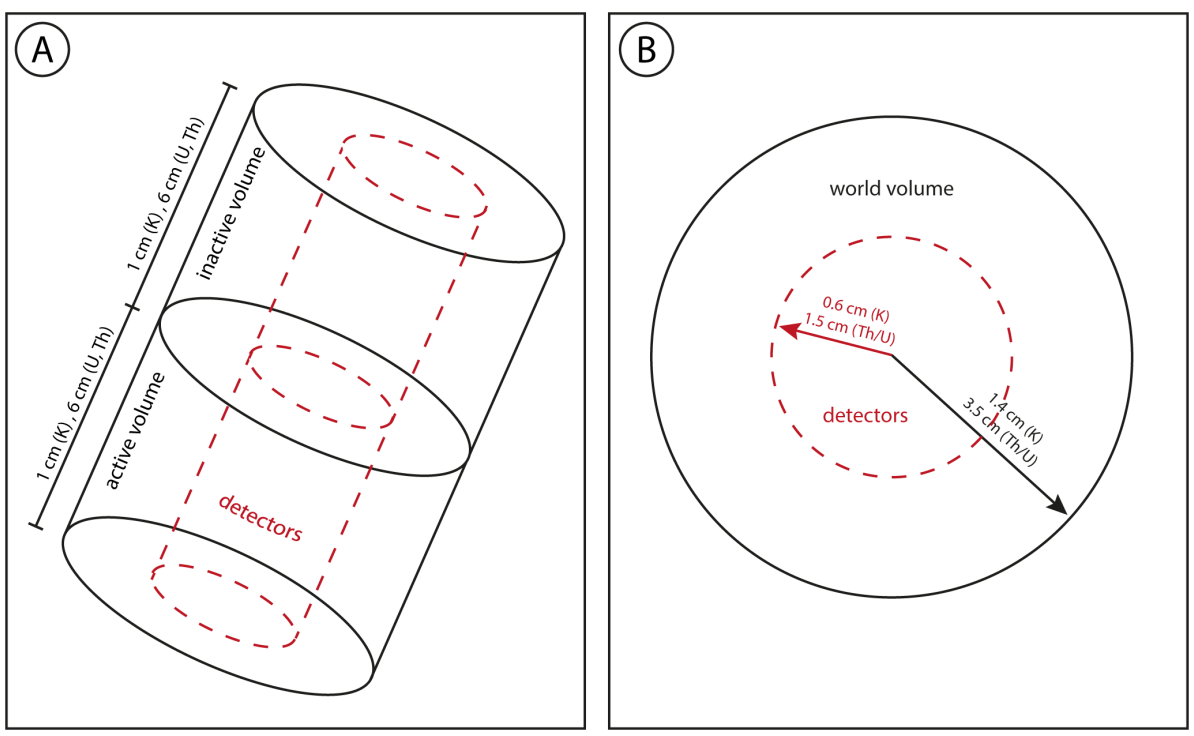

Fig. 3: Geometry used in the Geant4 simulations to obtain beta attenuation in an active and

534 inactive sediment matrix. To account for the longer range of the gammas, the detectors were changed to a thickness of $5 \mathrm{~mm}$ and radii of $86 \mathrm{~cm}, 125 \mathrm{~cm}$ and $115 \mathrm{~cm}$ for $\mathrm{K}$, Th, and $\mathrm{U}$ respectively. and a length of $70 \mathrm{~cm}$ for the active and inactive layers each. 

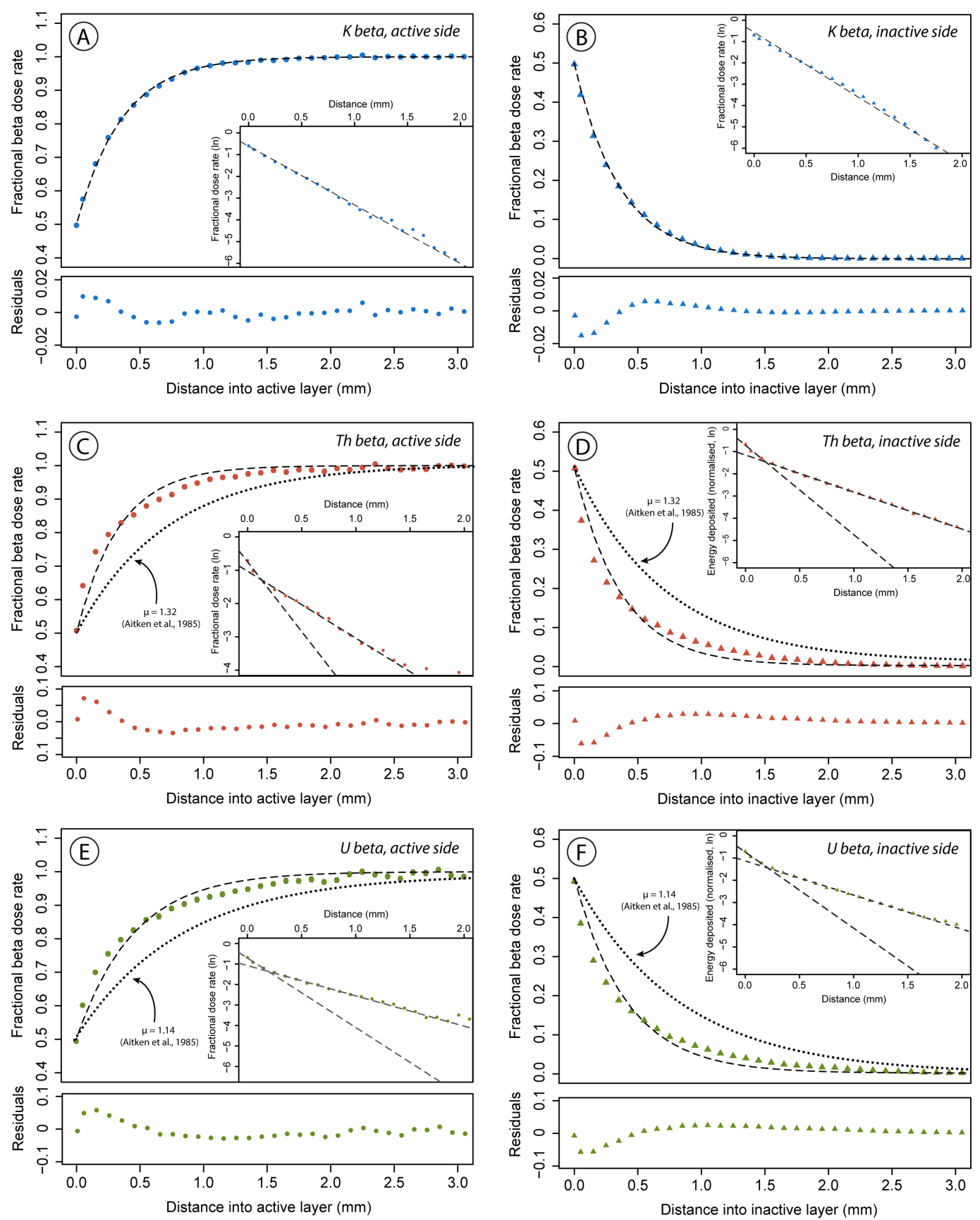

\begin{tabular}{|clll}
\hline Dose rate by ... on the active side & Dose rate by ... on the inactive side \\
$\mathrm{K}$ & $\mathrm{T}$
\end{tabular}

Fig. 4: A) $\mathrm{K}$ beta dose rate attenuation on the active side of the sediment matrix, B) $\mathrm{K}$ beta

540 dose rate attenuation on the inactive side of the sediment matrix, C) Th beta dose rate attenuation

541 on the active side of the sediment matrix, D) Th beta dose rate attenuation on the inactive side of

542 the sediment matrix, E) $\cup$ beta dose rate attenuation on the active side of the sediment matrix, F) $U$

543 beta dose rate attenuation on the inactive side of the sediment matrix. In the inserts, the normalised 

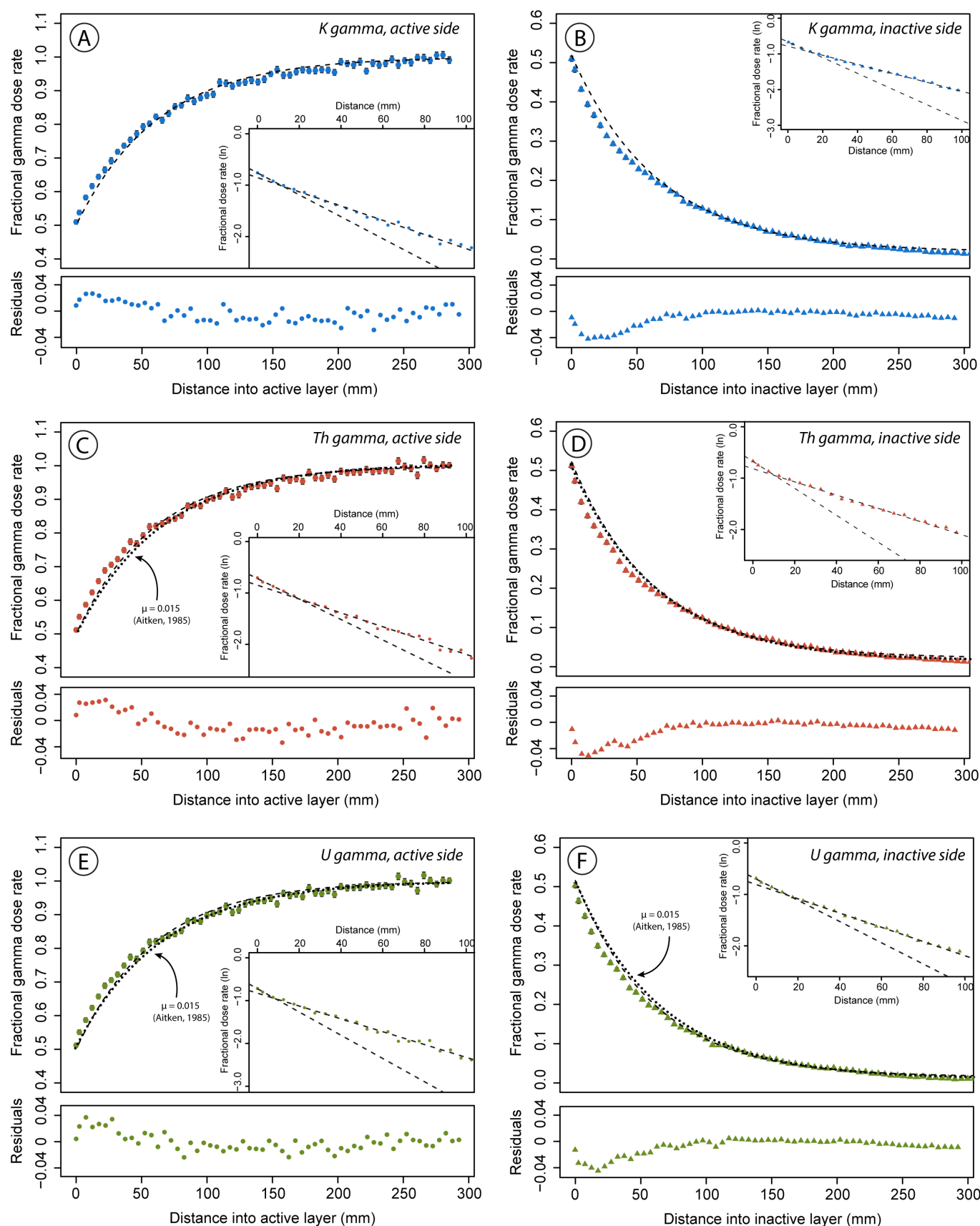

Dose rate by ... on the active side Dose rate by ... on the inactive side
$\mathrm{K}$

Fig. 5: A) K gamma dose rate attenuation on the active side of the sediment matrix, B) K

gamma dose rate attenuation on the inactive side of the sediment matrix, C) Th gamma dose rate 
550 inactive side of the sediment matrix, E) $U$ gamma dose rate attenuation on the active side of the

551 sediment matrix, F) $U$ gamma attenuation on the inactive side of the sediment matrix. In $B, D$ and $F$

552 the normalised dose deposited is presented as the natural logarithm of the original data, to highlight

553 the non-exponential attenuation for $\mathrm{K}$, Th and $\mathrm{U}$. 

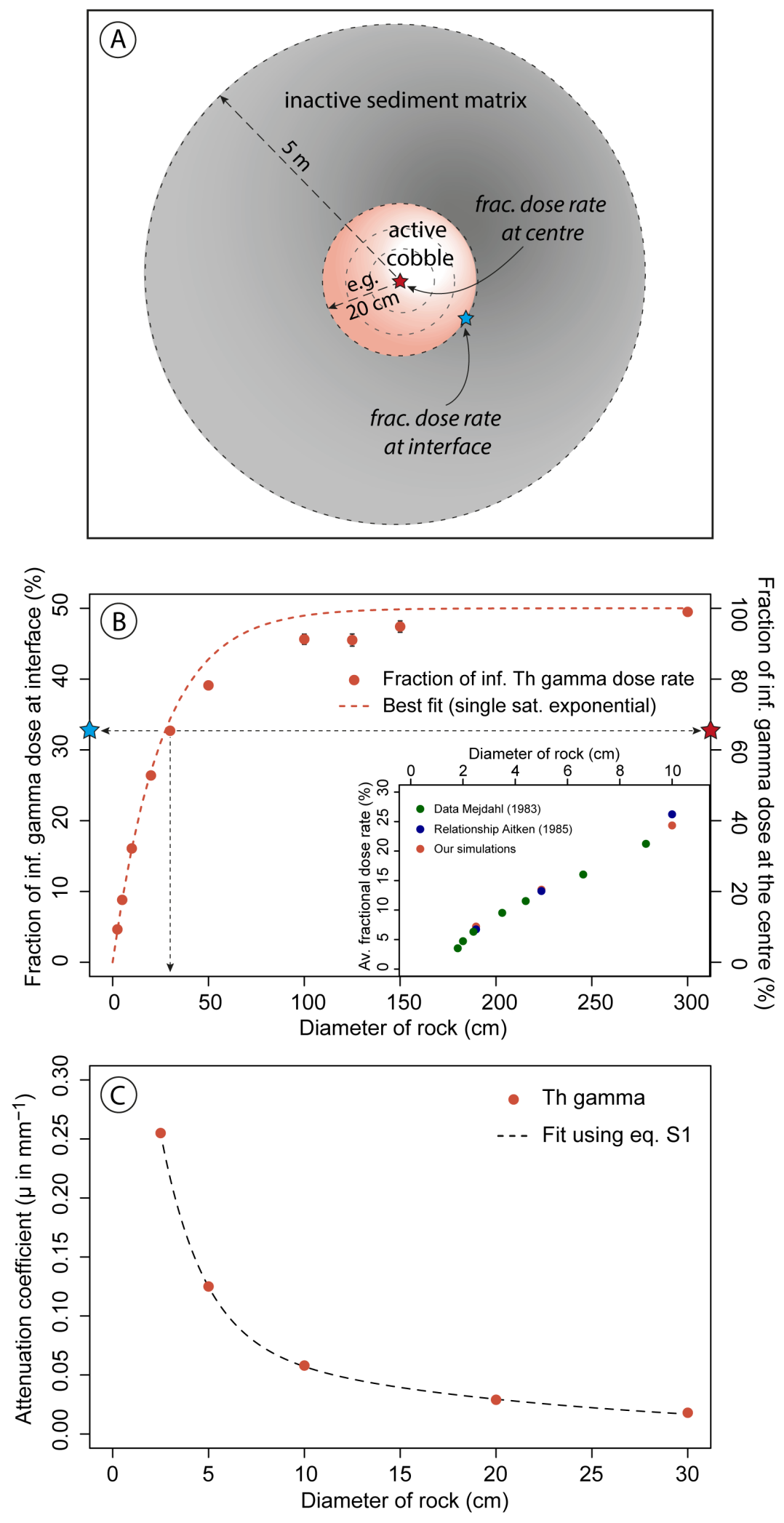

555 Fig. 6: A) Example for the simulation setup used to determine the fraction of the infinite gamma dose rate in the centre of the rock and at the interface of the rock and the adjacent sediment. In the 
557 case given here, the cobble has a diameter of $40 \mathrm{~cm}$. The dashed circles in the spherical rock are

558 displayed as an indication for the $1 \mathrm{~mm}$ thick concentric shells used in the simulations. Stars in Figure

5596 A correspond to the stars on the two y-axis in Figure 6B. B) Change of the fraction of infinite Th

560 gamma dose rate in the centre of the rock and at the interface as a function of rock diameter $(\mathrm{cm})$.

561 Th is given here as an example, since $\mathrm{K}$ and $\mathrm{U}$ show the same behaviour. The dashed lines and stars

562 correspond to the example of having a spherical rock with a diameter of $40 \mathrm{~cm}$, as shown in Figure

5636 A. The inset of B) shows a comparison of our simulation data (recalculated as average to be

564 comparable to the other two data sets), the data shown by Mejdahl (1983) and the relationship

565 proposed by Aitken (1985) based on Mejdahl (1983). The fractional dose rate here is the average

566 that the rock would receive of that particular size, not as in the other graphs at the interface or the

567 centre of the rock. C) Change of attenuation coeffiecient for Th gamma dose rates with rock size. A

568 table with obtained values for different sized rocks is available in the supplementary material, as

569 well as the equation used to fit the simulation data. Using equation S2 the user can obtain a precise

570 attenuation coefficient for each cobble size.

571

572 
574

575

576

577

578 $\mathrm{g} \mathrm{cm}^{-3}$ ) and absorption in sediment (density of $2.0 \mathrm{~g} \mathrm{~cm}^{-3}$ ). All values are expressed as $\mathrm{mm}^{-1}$.

\begin{tabular}{c|llll} 
& \multicolumn{4}{|c}{ Al absorber } \\
Decay chain & $\begin{array}{c}\text { Aitken et al., 1985 } \\
\text { (experiment) }\end{array}$ & $\begin{array}{l}\text { This study } \\
\text { (simulation) }\end{array}$ & $\begin{array}{l}\text { Aitken et al., 1985 } \\
\text { (calculation) }\end{array}$ & $\begin{array}{l}\text { This study } \\
\text { (simulation) }\end{array}$ \\
\hline K & NA & NA & NA & NA \\
Th & 1.78 & $1.79 \pm 0.03$ & 1.32 & $1.52 \pm 0.04$ \\
U & 1.54 & $1.49 \pm 0.03$ & 1.14 & $1.09 \pm 0.02$
\end{tabular}

\begin{abstract}
Table 1. Results of linear attenuation factors by Aitken et al. (1985) and results from this
study, when simulating their experimental setup. Values are given for absorption in Al (density of 2.7 Table 1. Results of linear attenuation factors by Aitken et al. (1985) and results from this
study, when simulating their experimental setup. Values are given for absorption in Al (density of 2.7
\end{abstract}

.

Table 2. Linear attenuation coefficients $\left(\mu \mathrm{mm}^{-1}\right)$ for beta radiation in sediment (composition according to Aitken, 1985), calculated using up to two linear regressions for In of $y$ values, with the onset of a second slope $(\mathrm{zmm})$ and its intercept $(\mathrm{f})$ given as well. . Linear attenuation coefficients $(\mu)$ for gamma radiation in sediment (composition according to Aitken, 1985) calculated using equation 1 and 2 , with the intercept (f) fixed to 0.5 . Uncertainties below $2 \%$ are not given.

\begin{tabular}{|c|c|c|c|c|}
\hline \multirow{2}{*}{ Decay chain } & \multicolumn{3}{|c|}{ Beta } & \multirow{2}{*}{ Gamma } \\
\hline & $\mu$ & $f$ & $z$ & \\
\hline $\mathrm{K}$ & $2.81 \pm 0.02$ & & - & 0.016 \\
\hline \multirow[t]{2}{*}{ Th } & $4.66 \pm 0.48$ & & & 0.016 \\
\hline & $1.84 \pm 0.04$ & 0.34 & $0.15 \mathrm{~mm}$ & \\
\hline \multirow[t]{2}{*}{$U$} & $3.52 \pm 0.25$ & & & 0.017 \\
\hline & $1.50 \pm 0.02$ & 0.37 & $0.15 \mathrm{~mm}$ & \\
\hline
\end{tabular}

. 
591

592

593

594

595

596 